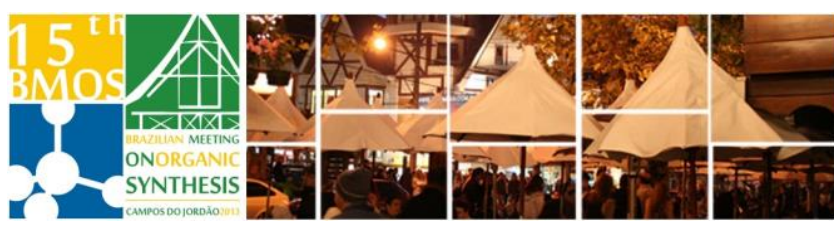

\title{
Solid Phase Synthesis of Hexapeptides and Solution Macrocyclization to Obtain Antiparasitic Agents
}

\section{Catherine Fagundez, ${ }^{a}$ Diver Sellanes, ${ }^{a}$ Andrea Medeiros, ${ }^{\mathrm{b},}$ Marcelo Comini, ${ }^{\mathrm{b}}$ Lindsay Stewart, ${ }^{c}$ Vanessa Yardley ${ }^{c}$ and Gloria Serra*a}

\author{
a Cátedra de Química Farmacéutica, Facultad de Química, Universidad de la República, G. Flores 2124,, \\ Montevideo, Uruguay, b Group Redox Biology of Trypanosomes, Institut Pasteur de Montevideo, \\ Montevideo, Uruguay, c Depto. de Bioquímica, c Infectious \& Tropical Disease, LSHTM, London, UK. \\ *gserra@fq.edu.uy
}

Keywords: macrocycles, solid phase, antimalarial, anti-trypanosomal.

\section{INTRODUCTION}

Hapalociclamide,

Aeruciclamides, and Microciclamides are bioactive hexacyclopeptides alternating in hydrophobic and hydrophilic (Ser, Thr and Cys) amino acids. ${ }^{1}$ The side chains of these polar amino acids are heterocyclized to form azoles. Seeking to further explore their biological activity, our group began a program to develop a route to macrocyclic analogs of natural products with antimalarial or antitrypanosomal activity. ${ }^{2}$ The long time required for solution synthesis of peptides encouraged us to explore the solid phase peptide synthesis (SPPS). This methodology diminishes the reaction time and the necessary amount of peptides could be obtained in excellent yields and purities.

In the present work the solid phase synthesis of different hexapeptides using $2 \mathrm{Cl}$-trityl and Wang resins, the macrocyclization reactions, the studies on cyclodehydration and the biological evaluation of the obtained compounds will be presented.

\section{RESULTS AND DISCUSSION}

Hexapaptides were obtained in high yields and good purities using SPPS.

Figure 1. Synthesis in Solid Phase
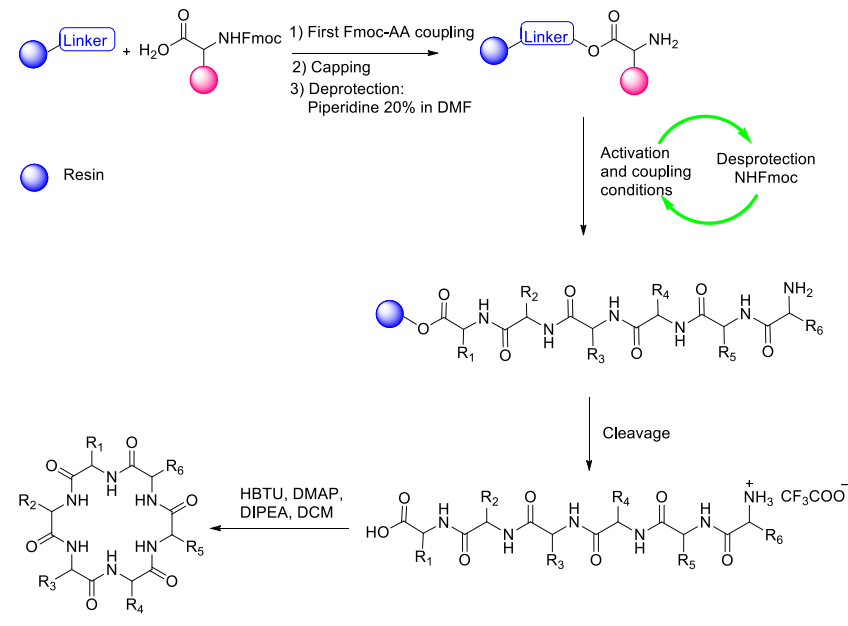

From the hexapeptides, the macrocyclic analogs of natural products were obtained in good yields (40$66 \%)$

In adittion, we investigated some cyclodehydration and oxidation reactions in solid phase, to produce azolines and azoles derived from hexapeptides containing Ser, Thr and Cys aminoacids.

The activities of the obtained compounds against Plasmodium falciparum K1, Trypanosoma brucei brucei and the cytotoxicities on murine macrophages (cell line J774) were evaluated.

\section{CONCLUSION}

In conclusion, good results were obtained combining solid phase and solution phase to obtain macrocycles. This strategy could be applied to obtain new potentially bioactive analogs.

Promising results were obtained for several compounds which present submicromolar antimalarial activity and micromolar antitrypanosomal activity and good selectivity for the parasites.

\section{ACKNOWLEDGEMENTS}

ANII,CSIC Grupos, PEDECIBA, UdelaR

\section{REFERENCES}

1 a) Gademann, K.; Kobylinska, J. The Chemical Record, 2009, 9, 187-198. b) Kaur, K.; Jain, M.; Kaur, T.; JainK, R. Bioorg. Med. Chem. 2009, 17, 3229-3256.

2 a) Peña, S.; Scarone, L.; Manta, E.; Stewart, L.; Yardley, V.; Croft, S.; Serra, G. Bioorg. Med. Chem. Lett. 2012, 22, 4994-4997. b) Peña, S.; Scarone, L.; Medeiros, A.; Manta, E.; Comini, M.; Serra, G. Med. Chem. Comm. 2012, 3, 1443-14 